\title{
Determinants and Stakeholders Influencing Children's Road Safety Education
}

\author{
Francisco Alonso ${ }^{1}$, Cristina Esteban ${ }^{1}$, Sergio Useche ${ }^{1}$, Violeta Manso ${ }^{2}$ \\ ${ }^{1}$ DATS (Development and Advising in Traffic Safety) Research Group, INTRAS (University Research Institute on Traffic and Road Safety), \\ University of Valencia, Valencia, Spain \\ ${ }^{2}$ Directorate-General of Traffic (DGT), Government of Spain, Madrid, Spain
}

Email address:

francisco.alonso@uv.es (F. Alonso), cristina.esteban@uv.es (C. Esteban), sergio.useche@uv.es (S. Useche), avmanso@dgt.es (V. Manso)

To cite this article:

Francisco Alonso, Cristina Esteban, Sergio Useche, Violeta Manso. Determinants and Stakeholders Influencing Children's Road Safety Education. International Journal of Elementary Education. Vol. 5, No. 6, 2016, pp. 63-68. doi: 10.11648/j.ijeedu.20160506.12

Received: October 28, 2016; Accepted: November 23, 2016; Published: December 27, 2016

\begin{abstract}
Road safety education is, widely, the best base and the greatest assurance of the future in terms of road safety prevention and promotion. Nowadays, RSE constitutes one of the main growing concerns in terms of complimentary education in many countries, taking into account, among other factors, the high rates of accidents that affect the health and welfare of childhood and adolescence. Furthermore, it is a necessity for the community health to create, train, encourage and lead positives attitudes for good road safety education. The general objective of this study was to describe the factors and stakeholders that have influence on the learning of road safety education and safe behaviors of children as road users. The results are very interesting. For example, when to parents have been asked about road safety education of their children, factors such as the parents influence and school environment have been considered as positive factors or stakeholders that influence on the road safety education of the children. Regarding children's opinion, most of the children consider that the drivers do not respect the rules never or sometimes, but only $5 \%$ of them believe that their parents do not respect the normative. However, a third part of the children reports signs of road aggression among their parents. Furthermore, $13 \%$ of the children do not feel safe when walks by their cities. This study shows the vital importance of the road safety education and key stakeholders, such as parents and the scholar system, to promote safe attitudes, behaviors and outcomes in terms of road safety. Also, the observed behaviors and circumstances related with road behavior of parents have an important influence on children's road safety education, that is crucial issue that must be addressed from different perspectives, due to high accident rates registered by children, who are a key population group to direct interventions in this regard, aiming to increase the effectiveness of interventions for welfare and health improvement, based on the child education.
\end{abstract}

Keywords: Road Safety Education, Children, Determinants of Road Safety, Influences on Road Safety, Parents

\section{Introduction}

The Road Safety Education (RSE) (or Traffic Safety Education) is, widely, the best base and the greatest assurance of the future in terms of road safety prevention and promotion. It is, currently, one of the greater concerns on education in many countries, taking into account, among other factors [1], the high rates of accidents that affect the health and welfare of childhood and adolescence [2, 3]. Furthermore, it is a necessity for the community health to create, train, encourage and lead positives attitudes for good road safety education [4].
Moreover, the road safety education is a really complex term, that implies many spheres of the life, and must be seen holistically [5]. However, for the road safety education reaches the status of "truly effective", it must be fulfilled a set of requisites and minimal conditions that the research experiences and the implementation programs conducted in different countries have been contributing to determine over the years. The historical perspective allows us to state that, in general, road safety education has been assumed as relatively poor on quality and temporally insufficient in most of the cases, due to the low assignment of resources and institutional efforts to improve it [6].

As concept, we can define road safety education as "any 
permanent educational action that stimulates the development of knowledges, skills, habits, behaviors, values and attitudes that improve the behavior of pedestrian, passenger or driver (in other words, every potential road user) with the ultimate aim of reducing the potential risk of suffering an accident and, ultimately, its rates [7].

In most of the countries, the road safety education for children is, nowadays, an important part of the national road safety policy. It becomes one of the main strategies to achieve high levels of road safety [8]. Despite this evidence, many countries have forgot to include, in a clearly and gradual manner, plans of road education in their official curriculums and to promote the growing of a "road safety culture" among all the road users [9]. In Spain, since almost a decade, road safety education has been established as a matter that aims to provide a comprehensive training and formation beyond of the traditional disciplinary contents [10].

This article aims to describe the determinants and influences on the road safety of the children from a scientific and interdisciplinary approach, supported by studies carried out by the "University Research Institute on Traffic and Road Safety (INTRAS)" and scientific articles of investigations and studies conducted in different countries and population samples, from diverse (but complimentary) perspectives [11-19].

We all agree that, typically, the responsible stakeholders assigned for children's road safety education are the parents or the school, which are considered positive factors influencing in the road safety of the children. The children notice and learn safe and unsafe behaviors from their parents a role model [16]. Those parents that do not respect the rules use to be considered as one of the main negative influences for road safety, being expressed in behavioral terms in later stages of life. As drivers, parents also have influence on the future behaviors of children. Several studies have shown that there are positive correlations in this field [7, 20]. Attitudes and behaviors observed in parents, regarding safe or unsafe driving; it affects the formation of favorable attitudes and conceptions of road safety among children [21]. There is a very clear influence: to greater safety awareness and behaviors performed by parents, greater safety awareness observed in children. This is known as an intergenerational transmission of the driver behavior [21]. Various studies have corroborated these correlations between parental driving styles and future driving styles and road behavior of children $[22,20,23,24,25,26]$.

The family atmosphere becomes another of the most important influence on attitudes about to driving by young [27]. A large set of variables has been studied, such as the respect for speeding limits, the interaction with other road users, the respect to the rules in stress situations, etc., and it has been observed how much do these factors influence in the future drivers [20].

According to the evidence, road safety education becomes to be determinant of a good reported road behavior. Since schools should implement age-appropriate interventions to promote safe attitudes and road behaviors, it is important to remark the importance to teach the children to act safely to the different situations of life, including driving [28].

According to previously reported statistics, most deaths from traffic accidents occurring in the population between 18 and 24 years old [29, 30], often due to preventable misbehaviors, such as the lack of seat belt use, driving under the influence of alcohol, driving using mobile phone, etc. [20]. This fact encourages us to implement road safety education programs from an early age, action that affects positively the raising of appropriate behaviors in the future [31]. One of the current challenges to create systematic and effective programs that involves both the school as the family is to reach a high level of integration between these two spheres, that are traditionally isolated or atomized [32].

Regarding theoretical approaches, the theory of planned behavior has been successful in changing attitudes in younger populations [33, 34]. There are documented experiences (in the mid and long term) of programs seeking to prepare young in anticipation of risks that would prevent dangerous situations [35].

It is debated whether it is more effective to impart the road safety education in the classroom or if this education be imparted by their parents. The studies shown that one should act from both sides if we are to succeed in this type of education [36]. As well, it has been used other complimentary strategies in the road educational programs, such as the testimony of the victims, although it has not reached conclusive results about its effectiveness [37]. Road education in the classroom, at school, is (however) the most used strategy in the education in this field. It aims to raise awareness and educate children in a correct perception of danger and appropriate behavior in their daily interaction with the road environment. Large studies have tried to see the relation between risk behavior and traffic accident, but unspecific conclusions are still inviting to grow the existing evidence on this topic [38].

Purpose of the Study

The general objective of this study was to describe the factors and stakeholders that have influence on the learning of road safety education and safe behavior of children as road users.

Regarding the significance of this study, it has to be mentioned that empirical evidence has demonstrated the importance of assessing the specific factors, agents and determinants that have influence on the effectiveness of road safety education of children. Furthermore, referring to the designing of future intervention strategies, it is fundamental to understand dynamics and processes that could explain potentially better outputs in RSE among Spanish children.

\section{Methods}

\subsection{Participants, Design and Instruments}

For the case of study, it was conducted a survey process taking into account both familiar groups as their children, in different cities of Spain. The age of the children for this study were between 8 years old to 12 years. The data was collected 
realizing 1267 interviews, of which 1079 were also been answered by children.

From the total of 1267 conducted interviews, regarding parents, the $35 \%$ of them were 39 years and the $39 \%$ had between $40-44$ years old. Finally, $19 \%$ of the parent's age were between $45-49$ years old and a $6 \%$ had 50 or more years old. $28 \%$ of the parents participating in this study were fathers, and the $72 \%$ were mothers. In the $94 \%$ of the families interviewed, parents were living together with the interviewed children.

The number of participants represents an error margin for the general data of \pm 2.75 with a $95 \%$ confidence interval in the most unfavorable case of $\mathrm{p}=\mathrm{q}=50 \%$.

\subsection{Data Processing}

In the case of this study, descriptive analyzes (frequencies and measures of central tendency) were taken, in order to describe and characterize the prevalence of factors associated with road safety education in Spanish children. In addition, comparative analyses with Chi-square (X2) were performed to discriminate the results according to the characteristics and habits of drivers who participated in the study.

Once the data was obtained, the relevant statistical analyses were performed using IBM SPSS (Statistical Package for Social Sciences), version 22.0.

\subsection{Ethics}

For this type of study, ethical approval and formal consent are not required. The research type described in the manuscript did not require the official intervention of the Ethics Committee in Experimental Research, (consultative and advisory body of the University of Valencia), as no personal data are used and the participation was anonymous. However, the Research Ethics Committee for Social Science in Health of the University Research Institute on Traffic and Road Safety at the University of Valencia was consulted, certifying that the research subject to analysis responds to the general ethical principles, currently relevant to research in Social Science, and issued a favorable opinion to carry out such research in Spain.

\section{Results}

The obtained results provided us with a whole range of influences, both positive and negative, on road safety education and perception among children and their parents.

First of all, when to parents have been asked about road safety education of their children, factors such as the parents influence ( $73 \%$ for mothers and $70 \%$ for fathers, concretely) and school environment (42\%) have been considered as positive factors or stakeholders that influence on the road safety education of the children. On the other hand, the drivers that do not respect the traffic rules $(21 \%)$ are considered as the main negative influence for the road safety education of children.

Regarding children's opinion, a $65 \%$ of the children consider that the drivers, in general, do not respect the rules never or sometimes; however, only $5 \%$ of them believe that their parents do not respect the normative. Moreover, 33\% of the children reports that their parents often use a bad language and get angry (or other signs of aggressive behavior) when they are driving.

Children who report that their parents do not respect driving rules indicated, also, that they do not respect, mainly, traffic lights or semaphores $(22 \%)$, and the existing speed limits (18\%), as shown in Table 1.

Table 1. Rules that parents do not use to respect (Road misbehaviors).

\begin{tabular}{ll}
\hline Rule / Misbehavior & Percent \\
\hline Traffic lights & $22 \%$ \\
The speed & $18 \%$ \\
Speak by mobile & $4 \%$ \\
Not using the seat belt & $3 \%$ \\
Not respect crosswalks & $2 \%$ \\
Not respect Stop & $2 \%$ \\
Go in the opposite direction & $2 \%$ \\
Others infringements & $6 \%$ \\
Not know /do not respect rules & $40 \%$ \\
\hline
\end{tabular}

It can be seen that there is a clear relationship between the number of situations experienced by parents as drivers and perception of their children. In other words, children which parents has not experienced any related situation with traffic the latest five years tends to assume or report that their parents always respect the rules $\left(\mathrm{X}^{2}=12.45 ; \mathrm{p}<0.001\right)$. Instead, the percentage of children who says that their parents do not respect traffic rules are statistically associated with the number of infringements sanctioned to their parents $\left(X^{2}=8.34 ; p<0.05\right)$.

Regarding the research results with respect to the security of the environment shows that $69 \%$ of the participant population of children say that they feel safer while walk by their city, and $13 \%$ claim that they do not feel safe. Furthermore, $18 \%$ reports that they, sometimes, feel safe and other times they do not, as shown in Figure 1.

Specifically, children tend to feel safer if they are accompanied (21\%), if people know them (16\%). On the other hand, the main reasons why they do not feel safe are the presence of cars $(13 \%)$ and of strange persons (10\%).

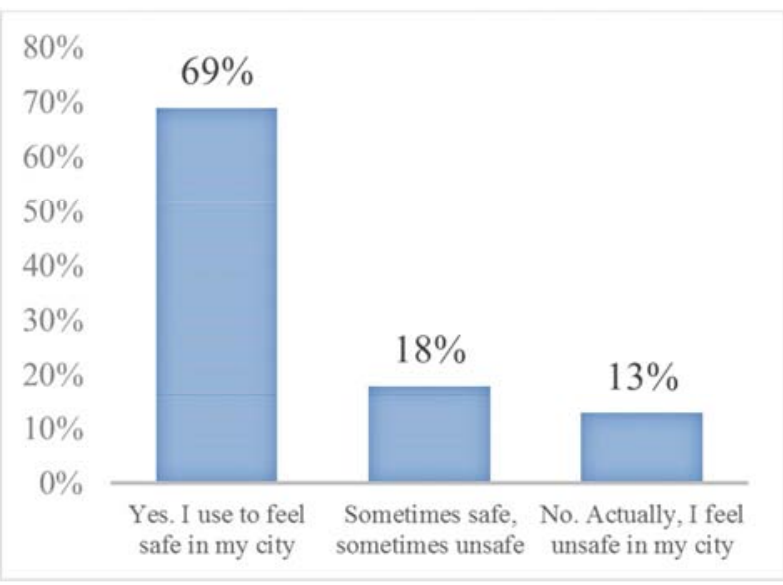

Figure 1. Do the children feel safe when they walk in their cities? 
Most of the children states also that, to feel safer in their city, it should occur changes related to road safety (43\%), most notably greater respect for traffic rules $(9 \%)$, to reduce traffic $(8 \%)$, to install more lights $(6 \%)$ and to make more parks and playgrounds for them $(6 \%)$. This data is contained in the Figure 2.

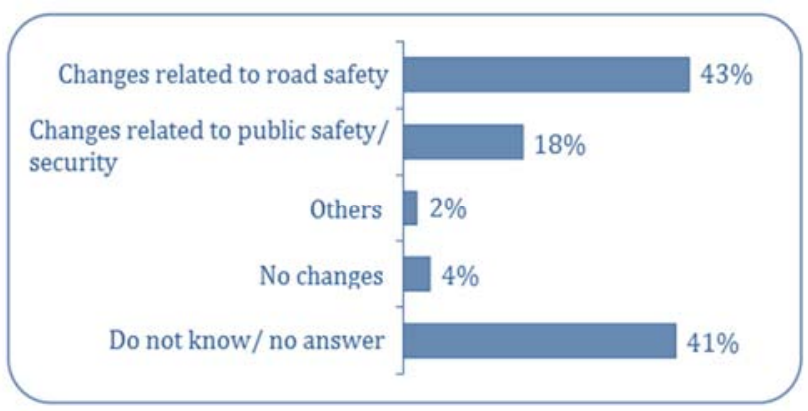

Figure 2. Changes that would be performed in the city to make it safer for children.

\section{Discussion}

Along the childhood and adolescence, it is very important to acquire a good education about key issues related to road safety, such as skills, attitudes and habits, which is necessary for live in the middle of a complex society and continuous change $[6,7]$. All this acquisition of information it is founded in a complex process that, in many countries, do not occupy a minimal space in their plans for primary and secondary studies [7]. This aspect must change in order to achieve greater awareness in the field of road safety for the entire population.

Road safety education becomes a holistic process, not a single fact or curricular action [39]. Since the official scholar curriculum must include this kind of topics and actions, it could be expected that it will have a direct impact on the life quality and welfare of people. In other words, they will contribute to the development of an appropriate civic and citizen awareness. However, the complimentary role of the involvement of parents is indisputable.

Moreover, the high rates of accidents registered by children makes important about what should be reviewed in these formation plans, on what role school plays and what role parents play. Both of them are important sources of influence, as shown by different studies $[5,27]$ and the results presented in this study. In short, the future behavior and attitudes of the child depend of many factors, but cannot constitute a mere accumulation of knowledge, but an integral approach, involving as many macro and micro-social agents as possible $[7,28]$.

There are many studies that show empirical evidences on the influence that the family and the school exercise in the children during their scholar formation period [21, 23]. What a child can observe in the behavior of his father or her mother, of their master or teacher, leads him to act in a similar manner based on the repetition of behavior [22]. It's crucial that families and school develop values of respect to the others, later potentially manifested in safer road behaviors (e.g.) behind the wheel, when crossing a crosswalk, and in each of the activities related with road using, all of them potentially affecting individual results in health and social behavior [40, 41].

In addition, those parents who respect the rules of road security become in a positive source of road safety education, and vice versa. Along this study, children have expressed how positive is the influence of the fact of their parents respect the rules. This become in big a set of influences and determinants for the children's road safety education, even involving the environmental and the security fields. Apart from the scholar system, the familiar atmosphere is, with no doubt, a valuable key in the acquisition of the respect guidelines and ethical that direct correlating with the future actions of those who are now children and teenagers [42].

We must be aware of the crucial and influential role of the school in road training of students to assume key road safety behavior in their everyday habits [39]. Governments should invest more in their budgets for road safety formation from school. Furthermore, it would require to impart more road safety education courses to complimentary stakeholders, such as parents and teachers, so they could properly teach this kind of knowledge and contents in house and school. Regarding educational plans and curriculums, it should include, widely, both educational and extracurricular activities (such as visits to road safety parks) $[6,43]$.

In brief, XXI century education cannot forget to analyze the determinants and influences on the road safety education of who, in short, will become adult citizens of our societies, and will represent potential positive (or negative) results in terms of road safety.

\section{Conclusions}

This study has shown the vital importance of the road safety education and key social agents, such as parents and the scholar system, as stakeholders influencing the development of attitudes, behaviors and outcomes in terms of road safety.

The observed behaviors and circumstances related with road behavior of parents have an important influence on children's road safety education.

Road safety education has become a crucial issue that must be addressed from different perspectives, due to high accident rates registered by children, who are a key population group to direct interventions in this regard.

Both school as families, and the society in general, should seek for needed resources, and create the tools and necessary climate to carry out this task. They exert enormous influence on future attitudes and behavior of children.

\section{Acknowledgments}

The authors wish to thank the Audi Corporate Social Responsibility program "Attitudes" (project No. UV20071472) for sponsoring the basic research. Also thanks 
to Mayte Duce for revisions of the text and to Iris Lacuesta and Leandro Garrigós for technical assessment.

\section{References}

[1] M. E. Pico Merchán, R. E. González Pérez, O. P. Noreña Aristazábal, "Seguridad vial y peatonal: una aproximación teórica desde la política pública". Hacia la promoción de la salud, 2011, 16, 2, pp. 190-204.

[2] Dirección General de Tráfico, "Investigación descriptiva sobre peatones y viajeros en edad escolar: exposición al riesgo y accidentalidad". España: D. G. T. (Dirección General de Tráfico). 1995.

[3] U. Trankle, C. Gelau, T. Metker, "Risk-perception and agespecific accidents of Young drivers". Accident analysis and prevention, 1990, 22, pp. 119-125.

[4] M. L. Cabrera Méndez, "Educación vial en Primaria". Innovación y experiencias educativas, 2011, p. 45.

[5] L. Malan, Van Dijk, Gerda, D. Fourie, "The strategy to align road safety education to the further education and training band curriculum". Africa Education Research, 2016, 13, pp. 132-146.

[6] F. Alonso, C. Esteban, C. Calatayud. "Personalización e individualización de programas. En Curso de educación vial para educadores extraescolares". Madrid: UNED. 2003.

[7] F. Alonso, C. Esteban, C. Calatayud, J. E. Medina, L. Montoro, Á. Egido, "Formación y educación vial. Una visión a partir de algunas prácticas internacionales". Cuadernos de reflexión Attitudes. Barcelona, 2003.

[8] J. P. Assailly, "Road safety education: what works?". Patient Education and Counseling, 2015, 5186.

[9] P. Baptista Lucio, J. Reyes Iturbide, "Los jóvenes y la educación para la cultura de la seguridad vial". Revista Panamericana de Pedagogía, 2014, 21, pp. 101-119.

[10] R. García-Ros, J. Gabriel Molina, J. P Ferrando, "Evaluación de la percepción de riesgo en la Educación Vial: desarrollo de una escala dirigida a escolares de Educación Primaria y Secundaria." Psicothema, 2001, 13, 2, pp. 234-239.

[11] F. Fylan, S. Stradling, "Behavioural change techniques used in road safety interventions for young people". European review of applied psychology / Revue europénne de psychologie appliquée, 2014, 64(3), pp. 123-129.

[12] J. M. Ibrahim, H. Day, J. M. Hirshon, M. El-Setouhy, "Road risk-perception and pedestrian injuries among students at Ain Shams University Cairo, Egypt". Journal of injury and violence research, 2012, 4(2), pp. 65-72.

[13] D. R. Poulter, F. P. McKenna, "Evaluating the effectiveness of a road safety education intervention for pre-drivers: an application of the theory of planned behavior". British journal of educational psychology, 2010, 80(2), pp. 163-181.

[14] E. Antonelli, "Self-bias e guida automobilistica: un confronto tra giovani e anziani italiani / Self-bias and driving: a comparison between young and older italian drivers". Rassegna di Psicologia, 2007 24(2), 129-152.

[15] L. Walker, D. Butland, R. W. Connell, "Boys on the road: masculinities, car culture and road safety education". The journal of men's studies, 2000, 8(2), pp.153-169.
[16] J. A. Thomson, K. Ampofo-Boateng, D. N. Lee, R. Grieve, T. K. Pitcairn, J. D. Demetre, "The effectiveness of parents in promoting the development of road crossing skills in young children". British journal of educational psychology, 1998, 68(4), pp. 475-491.

[17] K. Ampofo-Boateng, J. A. Thomson, "Child pedestrian accidents: a case for preventive medicine2. Health Education Research, 1990, 5(2), pp. 265-274.

[18] T. Rothengatter, "The role of media in road safety education for Young children". British journal of development psychology, 19842, (2), pp. 157-165.

[19] K. Pease, B. Preston, "Road safety education for Young children". British journal of education psychology, 1967, 37(3), pp. 305-313.

[20] B. Strukcinskiene, V. Giedraitis, J. Raistenskis, A. Martinkenas, V. Strukcinskaite, R. Stukas, S. U. Baysal, "Similarities between self-reported road safety behavior of teenage drivers and their perceptions concerning road safety of their parents". Transportation Reserarch Part F, 2014, 24, pp. 8-16.

[21] O. Taubman-Ben-Ari, O. Musicant, T. Lotan, H. Farah, "The contribution of parents' driving behavior, family climate for road safety, and parent-targeted intervention to young male driving behavior". Accident Analysis \& Prevention, 2014, 72, pp. 296-301. doi:http://dx.doi.org/10.1016/j.aap.2014.07.010

[22] O. Taubman-Ben-Ari, M. Mikulincer, O. Gilath, "From parents to children: similarity in parents and offspring driving styles”. Transportation Research Part F, 2005, 8, pp. 19-29.

[23] A. Brooks-Rusell, B. Simons-Morton, J. Ehsani, "Parents are the key to improving teen driving safety". Journal of adolescent health, 2014, 55, pp. 600-601.

[24] S. A. Ferguson, A. F. Williams, J. F. Chapline, D. W. Reinfurt, D. M. De Leonardis, "Relationship of parent driving records to the driving records of their children". Accident Analysis and Prevention, 2001, 33, pp. 229-234.

[25] R. J. Wilson, W. Meckle, S. Wiggins, P. J. "Cooper, Young driver risk in relation to parents retrospective driving record". Journal of Safety Research, 2006, 37, pp. 325-332.

[26] L. Bates, B. Watson, M. J. King, "The role of parents and nonparents in the supervision of learner drivers in Australia". Accident Analysis and Prevention, 2014, 70, pp. 40-45.

[27] O. Taubman-Ben-Ari, "Parents' perceptions of the family climate for road safety: associations with parents' self-efficacy and attitudes toward accompanied driving, and teens' driving styles”. Transportation Research Part F, 2016, 40, pp. 14-22.

[28] Y. Kitamura, "The possibility of holistic safety education in Japan: from the perspective of education for sustainable development (ESD)". IATSS Research, 2014, 38, pp. 40-47.

[29] WHO, "Global status report on road safety 2013: supporting a decade of action”. World Health Organization. Geneva, 2014.

[30] WHO, "Global status report on Road Safety: Time for Action". World Health Organization. Geneva, 2009.

[31] D. A. M. Twisk, J. J. F. Commandeur, W. P. Vlakveld, J. T. Shope, G. Kok, "Five road safety education programmes for Young adolescent pedestrians and cyclists: a multi-programme evaluation in a field setting". Accident Analysis and Prevention, 2014, 66, pp. 55-61. 
[32] M. Limbourg, D. Gerber, "A parent training program for the road safety education of preschool children". Accident Analysis and Prevention, 1981, 13, 3, pp. 255-267.

[33] I. Ajzen, "From intentions to actions: a theory of planned behavior". In J. Kuhl \& J. Beckmann (Eds.), "Action control: from cognition to behavior”. Springer Verlag, Berlin. 1985.

[34] I. Ajzen, "The theory of planned behavior". Organizational behavior and human decision processes, 1991, 50, pp. 179211.

[35] M. Markl, "Effectiveness of road safety educational program for pre-drivers about DUI: practical implication of the TPB in developing new preventive program in Slovenia". Transportation Research Procedia, 2016, 14, pp. 3829-3838.

[36] I. Van Schagen, T. Rothengatter, "Classroom instruction versus roadside training in traffic safety education". Journal of applied developmental psychology, 1997, 18, pp. 283-292.

[37] A. Cuenen, K. Brijs, T. Brijs, K. Van Vlierden, S. Daniels, G. Wets, "Effect evaluation of a road safety education program based on victim testimonials in high schools in Belgium". Accident analysis and prevention, 2016, 94.

[38] D. A. M. Twisk, J. J. F. Commandeur, W. P. Vlakveld, J. T. Shope, G. Kok, "Relationships amongst psychological determinants, risk behaviour and road crashes of young adolescent pedestriasn and cyclists: implications for road safety education programmes". Transportation Research Part F, 2015, 30, pp. 45-56.

[39] F. Alonso, C. Esteban, S.A. Useche, V. Manso, "Analysis of the State and Development of Road Safety Education in Spanish Higher Education Institutions". Higher Education Research, 1 [Publication in advance].

[40] J. A. Oxley, M. Congiu, M. Whelan, A. D'Elia, J. Charlton, "The Impacts of Functional Performance, Behaviour and Traffic Exposure on Road-Crossing Judgements of Young Children". Annual Proceedings - Association for the Advancement of Automotive Medicine, 2007, 51, pp. 81-96.

[41] D. C. Schwebel, A. L. Davis, E. E. O’Neal, "Child Pedestrian Injury: A Review of Behavioral Risks and Preventive Strategies". American Journal of Lifestyle Medicine, 2012, 6(4), pp. 292-302. doi:10.1177/0885066611404876.

[42] Morrongiello BA, Barton BK. Child pedestrian safety: Parental supervision, modeling behaviors, and beliefs about child pedestrian competence. Accident Analysis and Prevention. 2009; 41:1040-1046.

[43] M. M. Thein, J. Lee, "Road safety education for schoolchildren". World Health Forum, 1993, 14(4), pp. 407409. 